\title{
Early reading skills related to Grade 1 English Second Language literacy in rural South African schools
}

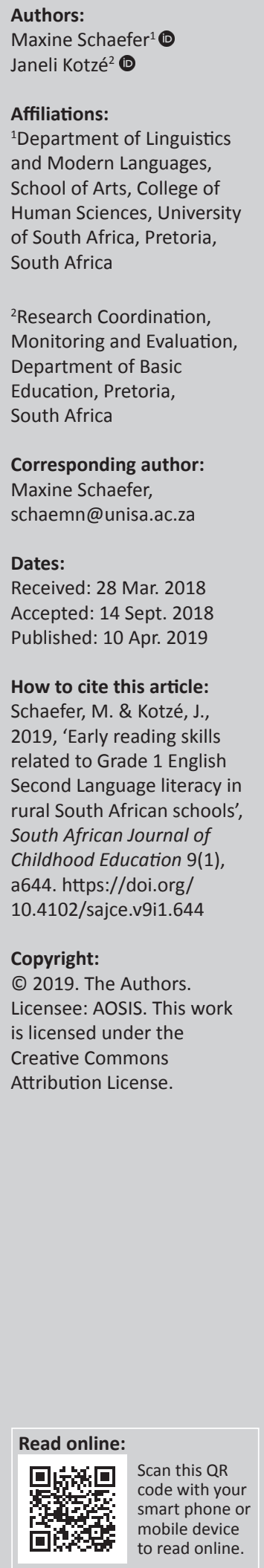

Background: Many South African children attend African language medium of instruction (MOI) schools, learn English as an additional language and switch to English MOI three years later. There is still much to be researched about how a child's first and second language literacy develops over time in South Africa.

Aim: This study aims to outline the first and second language skills at the start of Grade 1, which are associated with English Second Language literacy at the end of Grade 1 through the use of a longitudinal design.

Setting: Data was collected from 80 predominantly rural no-fee isiZulu and Siswati MOI schools in Mpumalanga.

Methods: A total of 1347 learners were randomly selected from these schools and were individually assessed on various first language (isiZulu or Siswati) and English skills at the start and end of Grade 1.

Results: The data show that learners begin school with varying first and second language oral language proficiency levels, and most learners are pre-literate. Decoding skills improved over the year, but $45.7 \%$ and $35 \%$ of learners were still unable to read a first language or English word correctly in $1 \mathrm{~min}$.

Conclusion: The data confirm the importance of first language phonological awareness and letter-sound knowledge for later word-reading abilities in isiZulu, Siswati and English, as well as their importance for English spelling. The study highlights the importance of the systematic development of English oral proficiency during the Foundation Phase especially for rural children who are not exposed to English in their communities.

Keywords: isiZulu; Siswati; English Second Language; literacy; transfer; longitudinal; highpoverty schools.

\section{Introduction}

Early literacy has taken centre stage as one of the most important aspects in ensuring sustained learning throughout an individual's schooling career. Through the acquisition and transfer of knowledge via reading and writing, literacy allows individuals to unlock their full potential and become better contributors to modern society. Literacy, therefore, does not only hold major benefits for the individual but also has spill-over effects on the broader society, and at a national level is associated with economic growth.

Literacy rates with respect to all languages are very low in South Africa, with $78 \%$ of Grade 4 learners not having reached the low international benchmark in their first language (L1) in the Progress in International Reading Literacy Studies (PIRLS) assessment in 2016 (Howie et al. 2017). Although the South African language policy promotes the teaching of reading in learners' L1 during the first three years of schooling, further learning from the fourth grade will most likely take place in English (ESL) ${ }^{1}$ for the majority of learners. This implies that learners do not only need to be able to read for meaning in their L1 but also in English.

The literacy issue is complicated in South Africa. Although the Language in Education Policy (South Africa 1996) allows for L1 education, most children have L1 education for the first three years of schooling only. Because of the perceived and real economic benefits of English literacy (Casale \& Posel 2011; Van der Walt \& Evans 2017), most children in South Africa will attend

1.In the South African curriculum, instruction in English as a second language (ESL) is referred to as English as First Additional Language because English is not necessarily a second language for most learners. However, to align with international literature, we will use the term ESL when referring to English as First Additional Language. 
schools that have English as the medium of instruction from Grade 4. Data from the 2013 Annual National Assessments showed that in Grades 1-3, 77\% of children completed their schooling in a language other than English, but in Grade 4, 90\% of children attended English medium schools (as cited in Pretorius \& Spaull 2016). The switch to English necessitates children developing their English oral language proficiency such that they can benefit from English reading instruction while supporting their L1 language and literacy abilities. This reality is acknowledged in the Foundation Phase (Grades 1-3) curriculum where additive bilingualism is advocated for to prepare learners for the switch to English as a medium of instruction from Grade 4 (Department of Basic Education 2011).

With regard to bilingual literacy, international literature has focused on what reading and language skills in the L1 are transferred to the second language (L2) or facilitate language and literacy acquisition in the L2 (Koda 2008). Knowing which skills facilitate language and literacy in L2 relies on the understanding of children's language and literacy skills in L1. There is unfortunately limited information from largescale studies in South Africa, which present information about the L1 African language literacy and language skill levels with which children begin school, and how these skills are transferred to or help facilitate language and literacy abilities in English L2 (ESL), especially in lower grades.

This paper, therefore, addresses the lack of knowledge regarding which L1 skills predict ESL language and literacy abilities in Grade 1 in South Africa through secondary analysis of the data from a large-scale study in 180 no-feepaying schools. Using the data collected through the evaluation of the Second Early Grade Reading Study (EGRS II), this paper focuses on the language and literacy abilities of learners in L1 and ESL at the start of schooling, and how these L1 and ESL competencies influence their first year of language and literacy development in formal schooling. The paper addresses two research questions:

- What are learners' L1 and ESL language and literacy abilities at the start and end of Grade 1 ?

- Which skills in L1 and ESL measured at the start of Grade 1 are predictors of ESL decoding and oral proficiency at the end of Grade 1?

\section{The foundations of reading comprehension: Word recognition, fluency and language proficiency}

There are many definitions of literacy, but here the cognitive definition is taken: being literate is the ability to construct meaning from a text (Grabe 2012; Hedgcock \& Ferris 2018). Reading comprehension is, therefore, the goal of literacy instruction. A necessary but not sufficient component for reading comprehension is fluent word-reading (Snowling \& Hulme 2005; Pretorius 2010), which itself relies on automaticity and accuracy in lower-level reading skills. These lower-level skills include phonological awareness (ability to attend to and manipulate the sound structure of a language; Adams 1990), word recognition (ability to recognise a printed word and to connect the visual print form to its phonological string and sematic meaning; Grabe 2012) and reading fluency (automatic and accurate word recognition; Fuchs et al. 2001; Hedgcock \& Ferris 2018). In addition, readers require an adequate vocabulary to enable reading comprehension (Nation 2013). Nation (2013) estimates that knowledge of 6000-9000-word families in English is needed to read a text with $98 \%$ coverage. Finally, children need to learn to connect letters to their sounds (Hulme \& Snowling 2015).

These reading skills are interrelated. Phonological awareness, specifically phoneme awareness, contributes to the development of letter-sound correspondence knowledge, which in turn improves phonological awareness (Adams 1990). Letter-sound knowledge and phoneme awareness contribute to accurate and fast word recognition, and accurate and efficient word recognition leads to fluent reading (Grabe 2012; Pretorius \& Spaull 2016). Vocabulary levels predict reading comprehension (Elleman et al. 2009; Grabe 2012), and the Lexical Restructuring Hypothesis (Metsala \& Walley 1998) argues that vocabulary knowledge can influence phonological awareness development. According to this theory, children develop more specific segmental phonological representations of words when exposed to new words; for example, children learn that [1] in lip is a phoneme which changes meaning when comparing it to the word hip (Goswami 2001; Wilsenach 2015). Furthermore, reading contributes to improved vocabulary (Cunningham \& Stanovich 2001). Finally, phonological working memory can constrain both reading and vocabulary development: children who cannot hold items in working memory will struggle to consolidate letter-sound correspondences and hold new vocabulary items in working memory long enough for their storage in long-term memory (Gathercole \& Baddeley 1993).

\section{Reading in a second language}

Word recognition, reading fluency and oral language proficiency in L2 are also needed to enable comprehension in L2 reading (Grabe 2012). However, one major difference between the acquisition of L1 and L2 literacy is that L2 readers do not always have access to a rich oral vocabulary in L2 (August et al. 2005); rather, L2 oral proficiency and L2 decoding proficiency develop simultaneously (Hedgcock \& Ferris 2018). Consequently, L2 reading comprehension may suffer if the child does not have the required vocabulary for the text, even though decoding abilities may be on par with L1 speakers (Geva 2006). In other respects, L2 literacy acquisition aligns with L1 literacy acquisition. Improved phoneme awareness, explicit phonics instruction, reading fluency, adequate vocabulary and text comprehension in L2 has been linked to better ESL literacy acquisition (August \& Shanahan 2006).

Reading in an additional language may be facilitated by L1 skills. According to the Linguistic Interdependence 
Hypothesis, some aspects of the languages of a bilingual reader share common proficiencies which can be transferred from L1 to L2, given sufficient automaticity of these proficiencies in L1 (Cummins 1979). The linguistic threshold hypothesis further states that transfer from L1 to L2 would likely only occur after a certain threshold level of proficiency in both the L1 and L2 (Cummins 1979). There are many criticisms of these hypotheses, for example, that the common underlying proficiencies shared between languages, and what a threshold entails, have not been explicitly defined (Genesse et al. 2006; Koda 2008; Grabe 2012). The focus of the current study, however, is not to evaluate these hypotheses but rather to use them as a basis to explain our analysis of predictive relationships from L1 (isiZulu and Siswati) to ESL.

Studies which examine the transfer of various L1s to ESL have found that both oral language proficiency skills (such as vocabulary) and decoding skills (such as phonological awareness and word recognition) transfer from L1 to ESL. Results from the Report of the National Literacy Panel on Language-Minority Children and Youth in the United States of America (August \& Shanahan 2006) found that L1 phonological awareness transfers both to ESL phonological awareness and ESL word-reading; L1 vocabulary transfers to ESL vocabulary (but probably as a consequence of the high frequency of cognates, which would not be expected between English and isiZulu or Siswati); L1 reading comprehension transfers to ESL reading comprehension; and better L1 readers were usually better L2 readers (Genesse et al. 2006). In a more recent meta-analysis of 47 studies of cross-linguistic transfer from various L1s to predominantly ESL, Melby-Lervåg and Lervåg (2011) reported moderate-to-strong correlations between L1 and ESL procedural skills related to decoding (phonological awareness and word recognition), whereas correlations between oral language proficiency in L1 and ESL were much weaker. They argue that the weaker correlations for oral language proficiency arise from this area of language proficiency being much more complex and therefore more difficult to measure. They included only studies where children received 4 or more hours of L2 instruction per day and reported only on cross-sectional data.

In summary, oral language and decoding skills from L1 can transfer to oral language and decoding skills in L2, although decoding skills are most amendable to transfer. While similar skills (such as inferencing, knowledge of genre conventions and comprehension monitoring) are used for reading comprehension in ESL and L1, ESL readers do not always have an adequate English vocabulary to aid their reading comprehension in English (Hedgcock \& Ferris 2018). The next section turns to research on ESL in South Africa and other African countries. We provide an overview of the low levels of both L1 and ESL literacy reported in some subSaharan African countries and provide evidence from small and larger quantitative studies which address the transfer of reading skills from $\mathrm{L} 1$ to ESL.

\section{English as a second language literacy and language abilities in South Africa and other African countries}

Data from South Africa show that children do not develop adequate lower-level reading skills in their L1, calling into question whether ESL decoding can benefit from L1 reading knowledge. Results from the Early Grade Reading Study, a Randomised Control Trial (RCT) in no-fee Setswana medium of instruction schools, provide some evidence for low L1 reading skills. Learners in the control schools of this study could correctly identify 5.4 letters and read 7.9 words on average in $1 \mathrm{~min}$ in Setswana at the end of Grade 1 (Taylor et al. 2016). This was an improvement from 5.08 mean letters correct per minute at the start of Grade 1 (Taylor et al. 2015). Spaull, Pretorius and Mohohlwane (2018) report that $17.77 \%$, $19.81 \%$ and $20.44 \%$ of their sample (total $N=740$ ) of Grade 3 Northern Sotho, Xitsonga and isiZulu readers in South Africa had zero scores on a grade level oral reading fluency passage. These children were assessed at the start of the Grade 3 year and attended schools where the medium of instruction matched their L1. Shin et al. (2015) report on L1 Chichewa reading in Grades 2 and 3 in Malawi. They do not provide summary statistics for their literacy assessments but remark on the 'high percentage of zero scores on many of the subtests' (Shin et al. 2015:263). In Ghana, data from the Early Grade Reading Assessment (EGRA) in 2015 found that $54.5 \%-92.5 \%$ of children at the end of Grade 2 could not read a single word correctly in a 1-min oral reading fluency task in L1 who attended school with the same language of instruction (Ghana Education Service 2016). EGRAs conducted in Uganda confirm this pattern: children at the start of Grade 1 could read no words correctly in any of the four L1s tested, which might be expected at the start of formal schooling (RTI International 2015). However, Grade 3 learners hardly had better reading skills in L1, with an average correct words per minute score of 0.4 and 2.8 at the start of the academic year (RTI International 2015). In summary, data from sub-Saharan Africa show that very basic L1 decoding abilities are quite low in Grades 1-3, calling into question how these skills can be used to facilitate literacy in English.

Research reports poor performance in ESL reading as well. Draper and Spaull (2015) examine the English oral reading fluency rates and silent comprehension of 1772 Grade 5 rural learners in South Africa. Learners who were tested in English and were not L1 speakers of English scored around 20\% on a grade level silent comprehension assessment, with about $40 \%$ of the sample reading slower than 40 words correctly per minute. In a second analysis of the above data which focused on the relationship between oral reading rates and comprehension, Pretorius and Spaull (2016) found that the Grade 5 learners sampled for the study had English-reading abilities similar to Latino ESL readers at Grade 1 Intermediate English speaker or Grade 2 Non-English speaker levels in Florida, United States. This leads the authors to conclude that 'whatever time is being spent on the mechanics of reading, it is ineffective and inadequate' (Pretorius \& Spaull 2016:1466). Research from Kenya found ESL oral reading fluency to be 
4.3 correct words per minute in Grade 1, and 17 correct words per minute in Grade 2 in control schools of the PRIMR Initiative (Primary Math and Reading; Piper et al. 2018). Thus, English-reading abilities of children at different grade levels also appear to be quite low.

With regard to oral language proficiency, small-scale research has shown that English vocabulary levels of ESL children in South Africa are low. Wilsenach (2015), using a cross-sectional design, examined the receptive vocabulary of 99 emergent Northern Sotho - English bilinguals using the Peabody Picture Vocabulary Test (PPVT) in the third term of Grade 1. She found that learners' receptive vocabulary levels in English were affected by the medium of instruction of the school. Learners who attended English medium schools had better English vocabulary. However, both groups' vocabulary was low compared to age norms for the PPVT (Wilsenach 2015). Pretorius and Stoffelsma (2017) also found low levels of English vocabulary for ESL children in high-poverty schools. Using a pretest posttest design, they examined the English vocabulary growth of 60 ESL third graders from the start of the year to the end of the year and compared this growth to that of 58 learners who attended an English medium school (and were mostly L1 speakers of English). The ESL children's receptive vocabularies at the end of third grade were about half the size of the L1 speakers given that the ESL Grade 3 learners are far less exposed to English than their English L1 counterparts. The study also confirmed Matthew effects in vocabulary development: vocabulary growth was slower for learners who began with a smaller vocabulary, and vocabulary growth was higher for learners who began with a larger vocabulary. These studies therefore confirm the importance of teachers in developing children's English proficiency.

Regardless of low levels of both L1 and ESL literacy in subSaharan Africa, evidence of transfer from L1 to ESL has been found. Shin et al. (2015) report that pretest Chichewa (a Bantu language from Malawi) reading skills (syllable identification, word recognition, word and sentence reading and reading accuracy) predicted posttest English reading and writing abilities in both Grades 2 and 3 after controlling for Englishreading abilities at each time point. Taylor and Coetzee (2013) provide indirect evidence of transfer from L1 to ESL in South Africa. They used a fixed-effects approach to estimate the longitudinal influence of the language of instruction in the Foundation Phase on academic achievement in later grades. Their analysis shows that compared to ESL learners who attended English medium schools during the Foundation Phase, the use of a learners' L1 as a medium of instruction in the Foundation Phase leads to better ESL proficiency in Grades 4-6. However, they also highlight that language use may not be the biggest contributor to academic success, citing community, school and home level factors as possible larger contributors. Data from small studies also provide evidence for language transfer. Wilsenach (2013) reported that L1 phonological awareness predicted ESL word-reading of Grade 3 Northern Sotho-English emergent bilinguals in
South Africa. De Sousa, Greenop and Fry (2010) found that L1 isiZulu phonological awareness transferred to ESL spelling in Grade 2 even though children had not received formal literacy instruction in isiZulu. Finally, Veii and Everatt (2005) found that L1 Herero phonological awareness predicted ESL word-reading in Namibia in Grades 2-5.

In contrast, at least one study has found that L1 reading skills do not transfer to ESL reading. Piper et al. (2018) report on the impact of two interventions in Kenya. One intervention targeted English and Kiswahili, which are languages of broader communication (PRIMR), and the other intervention targeted L1s of the children in addition to English and Kiswahili (PRIMR-MT). They hypothesised that if transfer occurs from L1 to English, learners who receive L1 instruction should perform better on the ESL literacy assessment. While both PRIMR and PRIMR-MT improved English and L1 literacy compared to control groups, the L1 instruction program had no additional impact on English than the PRIMR intervention, which focused only on English and Kiswahili. They, therefore, conclude that there were no language transfer benefits of improved L1 literacy on ESL literacy. They do however concede that a lack of transfer effects may have arisen from the different ways the programmes were implemented.

To conclude this section, data from five sub-Saharan countries show that children underperform in both L1 and ESL reading. Even so, there appears to be evidence of successful transfer from L1 to ESL reading abilities. There are, nevertheless, gaps in knowledge about L1 and ESL reading in South Africa in the following areas. Firstly, with regard to L1 reading, there is little known about isiZulu and Siswati reading abilities in a large sample of readers, especially in Grade 1. There are also no available quantitative studies on reading abilities in Siswati. Secondly, the majority of studies that examine reading in South Africa do not include both L1 and ESL measures of reading. Most research has also measured only reading abilities or oral language proficiency, whereas we attempt to measure both aspects. Lastly, the research on transfer from L1 to ESL reading has been limited to smaller sample sizes and cross-sectional studies. We use the data from the EGRS II to address these knowledge gaps.

\section{Teaching English as a second language in Grades 1-3}

The South African Curriculum and Assessment Policy Statement (CAPS) for English First Additional Language (EFAL) follows on from the research that highlights the key roles of decoding and oral language competence in ESL literacy. The CAPS covers four main learning areas (listening, speaking, reading and writing) with the integration of thinking, reasoning and language structure in the four areas (DBE 2011). The curriculum takes an additive bilingualism approach where EFAL proficiencies are meant to be built on L1 proficiencies. Additive bilingualism is the state where an additional language is learned in conjunction with the L1, so that both languages are used in parallel rather than the L1 
losing its positive status (Field 2004) The CAPS interprets additive bilingualism as enhancing transfer of literacy abilities from the L1 to ESL (DBE 2011:8). For example, if a learner can identify the letter ' $k$ ' in the L1, it is easier to build the English letter-sound knowledge of ' $k$ ' onto this. More instructional time can then be spent on areas where there are no similarities, for example, the voiceless dental click ' $c$ ' in cula (sing; isiZulu) compared to the voiceless velar plosive ' $c$ ' in cat (English).

The EFAL curriculum prioritises the development of English oral proficiency in the first grade with only incidental reading exposure, which gradually transitions to more explicit reading and writing instruction in Grades 2 and 3 (DBE 2011). The CAPS acknowledges that learners need to be proficient in English by the end of the third grade so that they can learn content subjects in English from Grade 4, stating '[learners'] progress in literacy must be accelerated in Grades 2 and 3' (DBE 2011:8). Additionally, the curriculum highlights that a 'substantial amount of time' needs to be devoted to EFAL instruction, especially for learners who have to transition to English as the language of instruction in Grade 4 (DBE 2011:9).

The EFAL curriculum, therefore, relies on the following assumptions:

- English oral proficiency is necessary for later English literacy acquisition.

- There is a strong L1 literacy foundation from which English literacy proficiencies can be developed.

- A total of 2-3 hours per week of English instruction for 3 years is sufficient for learners to develop the necessary vocabulary (conceptual and academic) in order to transition to English medium instruction in year 4 .

- Teachers are able to use English as the main language of instruction in EFAL lessons to increase learners' exposure to English.

A comparative curriculum analysis by Umalusi considered the Foundation Phase EFAL curriculum relative to the previous curriculum, the Revised National Curriculum Statement. The main recommendations from this review pertained to strengthening the teaching of the subject, rather than the content of the curriculum (Umalusi 2015). Similarly, an independent evaluation of the CAPS has shown that the weakness of the curriculum lies in its implementation rather than its contents (Department of Planning, Monitoring and Evaluation/DBE 2017).

\section{Research methods and design}

This study uses data from the first year of the EGRS II. The study is designed as an RCT, which aims to measure and compare the effects of two teacher-support interventions to the situation among a comparison group of learners who receive regular teaching. The interventions include structured lesson plans, reading coaches and additional material and focus on strengthening teachers' instructional practices for
EFAL. The study began in 2017 in 180 no-fee primary schools in the Mpumalanga province of South Africa and will continue until 2019. ${ }^{2}$

The focus of this paper is to provide evidence on the literacy and language skills of South African children in rural areas at the start of Grade 1, and how these skills predict reading in English at the end of the year. Given that we are interested in the general patterns of transfer from learners' L1 at the start of the year to ESL at the end of the year, and that instructional contexts do affect literacy transfer patterns (Kim \& Piper 2018), the results only consider the control group learners (80 schools) in the EGRS II. The paper reports data from the baseline assessment which was conducted with learners at the start of Grade 1 (January 2017), and from the midline assessment collected in the last month of the Grade 1 academic year (November 2017). At the start of 2017, 20 learners from each school were randomly selected, and a total of 3327 learners were assessed. Of these learners, 3040 $(91.37 \%)$ were reassessed at the end of Grade 1.

\section{Participants and school context}

Participant and school characteristics are presented in Table 1. The study participants are from the Gert Sibande and Ehlanzeni districts of Mpumalanga, a province in close proximity to Gauteng, but markedly more rural. All schools are no-fee schools (Quintile $\left.{ }^{3} 1-3\right)$ and have isiZulu (27\% of schools) or Siswati (73\% of schools) as the medium of instruction in the Foundation Phase. The majority of the principals in the survey described the location of the schools as remote rural, with a small number in a small village, township or informal settlement in a city. It can, therefore, be expected that learners in this study exhibit lower levels of literacy skills given that they are from no-fee schools which have a low socio-economic status (Taylor \& Yu 2009; Timæus, Simelane \& Letsoalo 2013) and are from rural rather than urban areas (DBE 2017; Howie et al. 2017). The average age of learners in the study was 6.65 years at the end of Grade 1. Learners' L1 mostly matched the language of the school, and $30 \%$ of learners reported themselves as L1 isiZulu speakers, with the remainder reporting themselves as Siswati speakers. With regard to parent or caregiver education, $60 \%$ of learners are from a household where the responding parent did not complete secondary schooling, and a further $26 \%$ only completed secondary schooling but have not pursued any further education. The parents were also asked some questions about how regularly they speak English to their child. $75 \%$ of the parents or guardian in this sample reported that they sometimes speak English to their children, but 28\%

2.As the study is still ongoing, this paper takes advantage of the data that have been collected, and does not aim to do any analysis on the interventions. For a full description of the EGRS II, as well as the impact of the interventions after the first year, see Kotzé, Fleisch and Taylor (2019).

3.In South Africa, public schools are grouped into quintiles which describe the wealth of the school, and therefore how much government funding they are entitled to. Quintile 5 schools are the 1 schools are the poorest. Quintile $1-3$ schools do not charge fees, and a large proportion of these schools participate in the National School Nutrition programme where learners receive a free meal at the school. These schools are legally not allowed to charge school fees and are usually the worst performing in the system. 
TABLE 1: Sample characteristics.

\begin{tabular}{|c|c|c|c|}
\hline Variables & $N$ & Mean & SE \\
\hline \multicolumn{4}{|l|}{ Learner characteristics } \\
\hline Learner $=$ Boy & 1347 & 0.53 & 0.02 \\
\hline Learner age at end of Grade 1 & 1347 & 6.65 & 0.02 \\
\hline Learner language $=$ Siswati & 1347 & 0.70 & 0.01 \\
\hline Parent education $=$ Did not complete secondary & 1329 & 0.60 & 0.01 \\
\hline Parent education = Only completed secondary & 1329 & 0.26 & 0.01 \\
\hline English at home $=$ Never & 1347 & 0.28 & 0.01 \\
\hline English at home $=$ Sometimes & 1240 & 0.75 & 0.01 \\
\hline Speak English to others $=$ Never & 1347 & 0.40 & 0.01 \\
\hline \multicolumn{4}{|l|}{ Teacher characteristics } \\
\hline Teacher age & 137 & 49.82 & 0.73 \\
\hline Older than 55 & 137 & 0.23 & 0.04 \\
\hline Teacher language = isizulu & 137 & 0.29 & 0.04 \\
\hline Teacher language $=$ Siswati & 137 & 0.67 & 0.04 \\
\hline Multi-grade classroom & 137 & 0.05 & 0.02 \\
\hline Class size & 137 & 42.80 & 0.91 \\
\hline Teachers have at least a bachelor's degree & 137 & 0.55 & 0.05 \\
\hline \multicolumn{4}{|l|}{ Principal and school characteristics } \\
\hline Principal age & 80 & 52.55 & 0.57 \\
\hline Older than 55 & 80 & 0.38 & 0.05 \\
\hline Quintile 1 school & 80 & 0.54 & 0.06 \\
\hline Quintile 2 school & 80 & 0.31 & 0.05 \\
\hline Quintile 3 school & 80 & 0.15 & 0.04 \\
\hline Ehlanzeni & 80 & 0.55 & 0.06 \\
\hline Gert Sibande & 80 & 0.45 & 0.06 \\
\hline LoLT = isiZulu & 80 & 0.27 & 0.05 \\
\hline LoLT = Siswati & 80 & 0.73 & 0.05 \\
\hline
\end{tabular}

$\mathrm{SE}$, standard error; LoLT, language of learning and teaching.

reported that they never speak English to their child. When asked how often their children speak English to anyone else, $40 \%$ of parents responded that their children never spoke English to anyone else. As with the country as a whole, the teachers in the study were relatively mature with an average age of close to 50 years, with almost a quarter of all teachers over 55 years old. All were female teachers.

\section{Instruments}

The baseline and midline learner assessment instruments used for this study were based on the EGRA (Dubeck \& Gove 2015). Each instrument was modified into Siswati and isiZulu to match the medium of instruction in each school. The instruments contained a number of tasks, some of which were similar across the baseline and midline (see Table 2). Both the baseline and midline assessments were designed to be orally administered by the fieldworkers to one learner at a time and to be captured electronically on Tangerine-TM software (RTI International 2018). To test the targeted 20 learners within one school day, the test was designed to take no longer than $15 \mathrm{~min}$ to administer. Because of these time constraints, it was not always possible to assess each skill in detail.

\section{Vocabulary}

Short vocabulary tasks which assessed farm animal knowledge were developed for the baseline and midline assessment. At baseline, all learners were administered a project-designed expressive vocabulary task in their L1
TABLE 2: Subtasks contained in the instruments at each time point

\begin{tabular}{|c|c|c|c|c|}
\hline \multirow[t]{2}{*}{ Construct } & \multicolumn{2}{|c|}{ Baseline - Start of Gr 1} & \multicolumn{2}{|c|}{ Midline - End of Gr 1} \\
\hline & L1 & English & L1 & English \\
\hline \multicolumn{5}{|l|}{ Language proficiency } \\
\hline Receptive vocabulary & - & $x$ & - & $x$ \\
\hline Expressive vocabulary & $x$ & $x$ & $x$ & $\mathrm{x}$ \\
\hline Listening comprehension & $x$ & - & - & $\mathrm{x}$ \\
\hline \multicolumn{5}{|l|}{ Decoding } \\
\hline Phonological working memory & $x$ & - & - & - \\
\hline Phoneme identification & $x$ & - & - & $x$ \\
\hline Letter-sound recognition & $x$ & - & - & $\mathrm{x}$ \\
\hline Word-reading fluency & $x$ & - & $x$ & $\mathrm{x}$ \\
\hline \multicolumn{5}{|l|}{ Spelling } \\
\hline Spelling of a CVC word & - & - & - & $x$ \\
\hline
\end{tabular}

CVC, Consonant - vowel - consonant; L1, first language; Gr, grade.

(either isiZulu or Siswati) and English. For both tasks, instructions and examples were given in the learners' L1. To assess L1 expressive vocabulary (12 items), learners were shown a picture of farm animals and asked, 'what is that?' while the enumerator pointed at the relevant animal. The same picture was used to elicit English vocabulary with the fieldworker, asking, 'what do we call this animal in English?' (three items). The animals named in the L1 and English tasks were different. Learners' receptive knowledge of English animal names was tested by asking the following question: 'show me the [animal name]' which required learners to point at the correct animal, after first being shown an example (three items). At midline, the same animal task was used to assess learners' English receptive vocabulary of farm animals (two items). An L1 expressive vocabulary task (five items) at midline was administered in which learners were shown pictures of children completing actions and had to identify the actions.

The limitations of assessing vocabulary in this way are noted. Other picture vocabulary tests such as the PPVT (used by Wilsenach 2015) and the Woodcock-Muñoz Language Survey (used by Pretorius \& Stoffelsma 2017) have been used with samples of South African children. Unfortunately, these tests are too time-consuming for the purposes of evaluating the EGRS II.

\section{Listening comprehension}

Because of learners' unfamiliarity with English at the start of Grade 1, an L1 listening comprehension task was administered. The enumerator read a short paragraph twice with expression about a girl playing in the rain. Learners were then asked four inferential questions about the story. At the end of Grade 1, an English version of the same paragraph was used for the English listening comprehension. Again, the passage was read twice with expression and learners were asked three of the same inferential questions about the text.

\section{English listening}

At midline, learners' knowledge of basic English instructions was assessed using a project-designed instructions task. This task required learners to perform a number of English instructions such as 'please stand up'. This task has not been used in EGRAs before. 


\section{Phonological working memory}

Phonological working memory was assessed in learners' L1 with a word span task (four items) and a non-word repetition task (five items) at the start of Grade 1. The word span task required learners to repeat a sequence of words in the same order as they were presented orally. The number of words per sequence increased from two to five. The nonword repetition task included the repetition of non-words of increasing difficulty: non-words increased in syllable number from two syllables to six syllables. The words chosen were similar for both isiZulu and Siswati and nonwords were created by making a few changes to existing words in the languages.

\section{Phoneme awareness}

An L1 phonological awareness task was administered at the start of Grade 1. After two examples, learners were asked to identify the first phoneme of two syllable real words (e.g. what is the first sound of gogo [grandmother]?). These words were similar in structure and meaning in isiZulu and Siswati. At the end of Grade 1, learners were administered phoneme identification tasks where they were asked to identify the first, last or middle sound of CVC English words (e.g. cat). A similar task is included in the standardised Comprehensive Test of Phonological Processing (Wagner, Torgesen \& Rashotte 1999). Three words were presented per condition. Learners were given bottle tops to reduce the cognitive load while performing the tasks. For each subtask, learners were presented with two examples, using the bottle tops to represent sounds at the start, end and middle of the word. Corrective feedback was provided in the examples, but not when the learner had to complete the non-example tasks.

\section{Letter-sound knowledge}

A letter-sound knowledge task was administered to learners at both points in time to assess their automatic knowledge of letter-sound correspondences. At the start of Grade 1, learners were asked to provide the isiZulu or Siswati (depending on their L1) letter sound for a maximum of 20 letters presented in a chart. At the end of Grade 1, learners were required to provide English letter-sounds for a maximum of 80 letters presented in a chart. Some English letters which are not pronounced the same as the L1 (such as ' $c$ ' pronounced [k] in English but as a voiceless dental click in Siswati) were included. For the most part, the English and L1 letter sounds are pronounced the same. Letters which sounded different in English compared to isiZulu and Siswati were only included 17th, 23rd, 28th, 34th and 58th in the chart. Learners were timed for $1 \mathrm{~min}$ and errors were recorded and subtracted from the total number of letters attempted. Learners' scores are reported as letters correct per minute.

\section{Word-reading fluency}

At baseline, learners were asked to read an isiZulu or Siswati word list (six words) depending on their L1. The words were all two syllables long and similar in structure in both languages. Because of floor effects, the results of the baseline word-reading task are not reported here. Learners completed a longer L1 word-reading task at midline (18 words). Learners read the L1 word list for one minute. Errors were recorded and subtracted from the total number of words attempted. Learners completed two English wordreading lists and were given $30 \mathrm{sec}$ to read from each list. One list contained CVC regularly spelled nouns, and one list contained high-frequency words from the Dolch sight word list (Dolch 1936). The number of words read correctly in each English word-reading task was added to derive a words correct per minute score.

\section{Spelling}

At midline, learners were shown a picture of a $d o g$, told it was a $d o g$ in English and were asked to write the word dog on a piece of paper. Learners were given a maximum of $2 \mathrm{~min}$ to complete this task.

\section{Data analysis procedure}

Index scores were created for phonological working memory (word span and non-word repetition) and English oral language proficiency (instructions, listening comprehension and vocabulary). To analyse the patterns of transfer from learners' L1 at the start of Grade 1 to English at the end of Grade 1, an ordinary least squares regression model was run on each of the midline assessment tasks. The models regressed each of the baseline tasks as explanatory variables and controlled for the sampling strata and the district. As a robustness check, these models were also run including various learner, teacher and school characteristics to increase the precision of the estimates. It was, however, evident that the coefficients of the baseline tasks did not change significantly with the inclusion of the additional controls, but that the sample size was reduced as a result of missing data. The additional controls were therefore not included in the reported models. To control for the clustering effect of learners in schools, standard errors were clustered at the school level.

\section{Ethical considerations}

The research methodology, with the intended instruments and research consent forms related to the baseline data collection, was formally submitted to the University of the Witwatersrand in May 2016. The project was approved on 03 November 2016 and was granted ethical clearance for the duration of the study up to 02 November 2019.

\section{Results}

\section{Literacy skills at the start and end of Grade 1}

Table 3 reports the descriptive statistics for each of the subtasks in both the baseline and midline assessment. The scores in the table have not been standardised and the averages should, therefore, be interpreted relative to the minimum and maximum value in the range column. For example, in the baseline expressive vocabulary task, the average performance was 7.2 items correct out of 12 . Learners at the 10 th percentile 
TABLE 3: Sub-test descriptive statistics.

\begin{tabular}{|c|c|c|c|c|c|c|c|c|c|c|c|c|c|}
\hline Time & Variable & $N$ & Reliability & Mean & SE & p10 & p25 & p50 & p75 & p90 & Min. & Max. & Proportion of zero scores (\%) \\
\hline \multirow[t]{8}{*}{ Start Gr1 } & 1. L1 expressive vocabulary & 1347 & 0.67 & 7.15 & 0.04 & 4.0 & 6.0 & 7.0 & 9.0 & 10.0 & 0.0 & 12.0 & 1.5 \\
\hline & 2. L1 word span & 1347 & 0.76 & 9.98 & 0.04 & 7.0 & 9.0 & 10.0 & 12.0 & 13.0 & 0.0 & 14.0 & 1.0 \\
\hline & 3. L1 non-word repetition & 1347 & 0.58 & 4.21 & 0.02 & 3.0 & 4.0 & 5.0 & 5.0 & 5.0 & 0.0 & 5.0 & 1.2 \\
\hline & 4. L1 phoneme isolation: First & 1347 & 0.87 & 1.13 & 0.03 & 0.0 & 0.0 & 0.0 & 2.0 & 4.0 & 0.0 & 6.0 & 62.4 \\
\hline & 5. L1 listening comprehension & 1347 & 0.51 & 2.13 & 0.02 & 1.0 & 1.0 & 2.0 & 3.0 & 4.0 & 0.0 & 4.0 & 8.9 \\
\hline & 6. L1 letters correct per minute & 1347 & - & 6.98 & 0.14 & 0.0 & 1.5 & 4.5 & 9.0 & 18.0 & 0.0 & 30.0 & 18.0 \\
\hline & 7. ESL vocabulary & 1347 & 0.52 & 0.84 & 0.02 & 0.0 & 0.0 & 0.0 & 1.0 & 2.0 & 0.0 & 6.0 & 50.4 \\
\hline & 8. Index: Phonological working memory & 1347 & 0.41 & 0.00 & 0.02 & -1.2 & -0.4 & 0.2 & 0.7 & 1.0 & -4.9 & 1.5 & - \\
\hline \multirow[t]{12}{*}{ End Gr1 } & 9. L1 expressive Vocabulary & 1347 & 0.40 & 4.90 & 0.01 & 5.0 & 5.0 & 5.0 & 5.0 & 5.0 & 0.0 & 5.0 & 0.2 \\
\hline & 10. L1 words correct per minute & 1347 & - & 5.54 & 0.12 & 0.0 & 0.0 & 1.0 & 12.0 & 17.0 & 0.0 & 18.0 & 45.7 \\
\hline & 11. ESL phoneme isolation: First & 1347 & 0.89 & 1.79 & 0.02 & 0.0 & 0.0 & 2.0 & 3.0 & 3.0 & 0.0 & 3.0 & 31.1 \\
\hline & 12. ESL phoneme isolation: Last & 1347 & 0.87 & 1.42 & 0.02 & 0.0 & 0.0 & 1.0 & 3.0 & 3.0 & 0.0 & 3.0 & 43.7 \\
\hline & 13. ESL phoneme isolation: Middle & 1347 & 0.83 & 0.62 & 0.02 & 0.0 & 0.0 & 0.0 & 1.0 & 3.0 & 0.0 & 3.0 & 70.3 \\
\hline & 14. ESL letters correct per minute & 1347 & - & 17.62 & 0.31 & 0.0 & 4.0 & 13.0 & 27.0 & 41.0 & 0.0 & 80.0 & 10.6 \\
\hline & 15. ESL words correct per minute & 1346 & - & 5.16 & 0.13 & 0.0 & 0.0 & 2.0 & 8.0 & 16.0 & 0.0 & 36.0 & 35.0 \\
\hline & 16. ESL listening & 1347 & 0.78 & 2.66 & 0.02 & 0.0 & 2.0 & 3.0 & 4.0 & 4.0 & 0.0 & 5.0 & 12.8 \\
\hline & 17. ESL listening comprehension & 1347 & 0.84 & 0.17 & 0.01 & 0.0 & 0.0 & 0.0 & 0.0 & 1.0 & 0.0 & 3.0 & 85.9 \\
\hline & 18. ESL vocabulary & 1345 & 0.54 & 0.48 & 0.02 & 0.0 & 0.0 & 0.0 & 1.0 & 2.0 & 0.0 & 2.0 & 66.0 \\
\hline & 19. ESL spelling & 1342 & - & 0.24 & 0.01 & 0.0 & 0.0 & 0.0 & 0.0 & 1.0 & 0.0 & 1.0 & 75.6 \\
\hline & 20. Index: English oral language proficiency & 1342 & 0.47 & 0.00 & 0.03 & -1.4 & -0.7 & -0.3 & 0.6 & 1.3 & -1.4 & 4.3 & - \\
\hline
\end{tabular}

Note: Treatment, district and stratification dummies controlled for. Standard errors are clustered at school level.

$\mathrm{SE}$, standard error; p, percentile; ESL, English as a second language; L1, first language; Gr, grade; Min., minimum; Max., maximum.

$*, p<0.05 ; * *, p<0.01 ; * * *, p<0.001$.

of the performance distribution on this item managed to score four items correct on average, whereas learners at the 90th percentile managed to score 10 out of the 12 correct. The table shows that in some of the subtasks there were floor effects (e.g. phoneme awareness), and two items had a ceiling effect (e.g. baseline non-word repetition and midline expressive vocabulary). Knowledge of English vocabulary was low, with only $25 \%$ of the sample correctly identifying at least one animal in English. Overall, both the assessments seem to provide enough information to discriminate among learners at various parts of the performance distribution.

In general, there is variability in learners' vocabulary levels, phonological working memory and listening comprehension ability at the start of Grade 1. Learners have varying levels of letter-sound knowledge with half the learners naming five or fewer letters correctly in a minute, and $18 \%$ of learners not being able to identify a single letter correctly. Most learners were unable to identify the first phoneme of a two-syllable word in their L1, with learners only at the 75th percentile able to identify two of six phonemes correctly. Half the learners could not name or point to farm animals in English, and even at the 90th percentile, learners could identify only two of six animals.

By the end of Grade 1, most of these skills showed improvements, but there were still large numbers of zero scores in the sample. With regard to word-reading, learners at the 50th percentile could read one L1 word correctly; while this was zero below the 50th percentile, at the 90th percentile learners could read 17 words per minute correctly. Similar results were found for ESL word-reading. Learners below the 50th percentile could not perform English phoneme identification tasks correctly by the end of Grade 1. Learners could recognise more letter-sounds correctly on average moving from a mean of 6.98 at the start of the year to a mean of 17.62 by the end of the year. However, learners at the 10th percentile were still unable to identify a letter correctly in the given time at the end of Grade 1. Overall, learners' knowledge of English vocabulary is low with regard to the listening to instructions task; learners on average managed to correctly respond to about three of the five instructions given in English. The listening comprehension and the English expressive vocabulary tasks proved to be more difficult. Learners managed to correctly answer one of the listening comprehension questions only at the 90th percentile and at the 75th percentile they managed to give the correct English word for a picture. Only learners at the 90th percentile were able to spell the English word dog.

\section{First language and English as a second language skills associated with literacy at the end of Grade 1}

Each column in Table 4 shows the result of separate regressions run on each of the subtasks in the end of Grade 1 assessment. The table reports on the coefficients of the baseline assessment tasks, as well as the average performance of each of the midline subtasks (as shown in the last row). The coefficient on each of the predictors can, therefore, be interpreted as the increase or decrease in the average score associated with a one-point increase in the predicting subtask score, if all the other variables are kept constant.

L1 vocabulary at the start of Grade 1 showed significant positive associations to L1 vocabulary at the end of the year but had no other statistically significant associations with the other end of Grade 1 tasks. L1 phonological working memory had a significant positive association with ESL phoneme 
TABLE 4: Regression coefficients and standard errors of start of Grade 1 variables as predictors of end of Grade 1 variables.

\begin{tabular}{|c|c|c|c|c|c|c|c|}
\hline Start of Gr1 Variable & L1 Vocab & L1: Words & ESL: PA & ESL: Letters & ESL: Words & ESL: OLP & ESL: Spelling \\
\hline L1 Vocab & $0.011 *(0.005)$ & $0.082(0.107)$ & $0.01(0.046)$ & $0.127(0.277)$ & $0.157(0.106)$ & $0.02(0.014)$ & $0.004(0.006)$ \\
\hline L1 phonological working memory & $0.019(0.013)$ & $0.234(0.175)$ & $0.188 *(0.089)$ & $0.544(0.458)$ & $0.129(0.171)$ & $0.033(0.027)$ & $0.004(0.016)$ \\
\hline L1 phoneme identification & $-0.005(0.005)$ & $0.506 * *(0.154)$ & $0.314 * * *(0.066)$ & $0.972 * *(0.329)$ & $0.466 * *(0.159)$ & $0.022(0.019)$ & $0.029 * *(0.009)$ \\
\hline L1 listening comp. & $0.01(0.009)$ & $0.128(0.150)$ & $0.296 * * *(0.074)$ & $0.61(0.436)$ & $-0.055(0.188)$ & $0.051 *(0.020)$ & $-0.006(0.011)$ \\
\hline L1 letter sounds & $0.003 *(0.001)$ & $0.265 * * *(0.047)$ & $0.047 * *(0.016)$ & $0.627 * * *(0.111)$ & $0.232 * * *(0.048)$ & $0.016 * * *(0.004)$ & $0.013 * * *(0.003)$ \\
\hline ESL vocabulary & $-0.019(0.013)$ & $0.303(0.205)$ & $0.117(0.095)$ & $0.673(0.532)$ & $0.349(0.215)$ & $0.317 * * *(0.038)$ & $0.045 * * *(0.012)$ \\
\hline$R$-squared & 0.022 & 0.169 & 0.137 & 0.154 & 0.136 & 0.225 & 0.169 \\
\hline Average mean & 4.897 & 5.049 & 3.625 & 16.663 & 5.029 & 0.281 & 0.235 \\
\hline
\end{tabular}

Note: Treatment, district and stratification dummies controlled for. Standard errors (indicated in parentheses) are clustered at school level.

Comp, comprehension; Vocab, vocabulary; PA, phoneme awareness; OLP, oral language proficiency; ESL, English as a second language; L1, first language.

$*, p<0.05 ; * *, p<0.01 ; * * *, p<0.001$.

awareness. L1 phoneme identification was strongly associated with increased L1 and ESL word-reading, ESL phoneme awareness, ESL letter-sound recognition, ESL spelling. L1 listening comprehension measured at the start of Grade 1 was positively associated with ESL phonemic awareness and ESL oral language proficiency. L1 letter sounds at the start of Grade 1 showed significant positive associations with all other subtasks at the end of Grade 1. ESL vocabulary at the start of Grade 1 showed significant positive associations with ESL oral language proficiency and spelling.

\section{Discussion}

This study considers the skills related to ESL literacy after the first year of formal schooling in South Africa. The majority of South African learners are ESL but will be required to learn their content subjects in English from Grade 4. It is, therefore, imperative to understand how English decoding and oral proficiency develop alongside learners' L1. This knowledge can inform teaching practice and, with the inclusion of future waves of data collection, can help teachers identify learners at risk of reading failure. The learners sampled in the EGRS II are predominantly from rural areas in Mpumalanga with either Siswati or isiZulu as the medium of instruction in the Foundation Phase. They attend no-fee Quintile 1-3 schools, do not have well-educated parents and are taught by teachers who are mainly ESL speakers.

\section{First language and English as a second language oral proficiency and literacy at the start and end of Grade 1}

Because of a lack of quantitative research on isiZulu and Siswati in Grade 1, our first research question addresses the language and literacy abilities with which children begin and end Grade 1.

With regard to oral language proficiency at the start of Grade 1, there was variation in the L1 oral proficiency of learners, measured through a project-designed vocabulary task which required learners to give the isiZulu or Siswati name for animals in a picture. The listening comprehension task also showed variation. Differences in vocabulary among learners may be a result of various emergent literacy, home and community factors. Learners, therefore, start school with different experiences with their L1, which can affect later reading performance (Ntuli \& Pretorius 2005). Given that a standardised vocabulary test was not administered, it is difficult to make claims about vocabulary per se. Rather, teachers should be aware that not all learners have had the same listening and speaking experience in their L1 and should incorporate explicit L1 vocabulary instruction in their classrooms alongside their reading instruction. ESL vocabulary knowledge was more homogenous with 50\% of learners not being able to correctly identify or say an English animal name when prompted with a picture.

By the end of Grade 1, L1 expressive vocabulary showed no variation, possibly because of the task not being sensitive enough. IsiZulu and Siswati vocabulary development is, therefore, an area for further research. The ESL oral language proficiency tasks showed that children were beginning to understand English, but they still have a far way to go if they are to become proficient English users. Children performed best in the English listening task where they had to demonstrate their understanding of English instructions by performing actions. This is a skill included in the curriculum for Grade 1 (DBE 2011:11), and our results suggest that teachers do focus on teaching simple English instructions. However, learners did not yet have an English vocabulary sufficient to understand a short story read to them. The English listening comprehension was translated from the L1 listening comprehension administered at the start of Grade 1. Comparing L1 $(M=2.13)$ and ESL $(M=0.17)$ results in the same text show that learners are emergent bilingual after the first year of English instruction. The English that learners in this sample are exposed to outside of school is limited. About $40 \%$ of parents reported that their children never speak English to someone else and 75\% reported that English is only spoken sometimes at home. Given the education levels of the parents, it is expected that both the quantity and complexity of the English spoken at home is not sufficient for the academic school context.

Our results emphasise the challenge that learners face in South Africa, where they will eventually need to complete all their learning in English after only having had 3 years of ESL instruction in the Foundation Phase. This highlights the need for a structured approach to the teaching of English oral proficiency in the Foundation Phase and also highlights the central role of teachers to develop ESL language proficiency 
in rural contexts such as this. Story book reading is one possible solution to developing learners' L1 and English vocabulary (Ntuli \& Pretorius 2005).

With regard to decoding, we consider the phonological processing skills, which include phonological working memory and phoneme awareness, under decoding skills. We also address letter knowledge and word-reading fluency. Phonological working memory was measured at the start of Grade 1 to account for differences in later reading ability because of its involvement in vocabulary and letter learning (Gathercole \& Baddeley 1993). Phonological working memory (word span and non-word repetition) capacity varied in the sample, but more research is needed to establish norms in this grade and in these language groups. L1 first phoneme isolation at the start of Grade 1 showed floor effects, indicating that the majority $(63 \%)$ of children in this sample had not yet developed L1 phoneme sensitivity. This may be expected considering that learners were assessed at the start of the Grade 1, that is, at the start of formal literacy instruction. At the end of Grade 1, more learners displayed phoneme sensitivity to initial, middle and final sounds of CVC English words. Only $31 \%$ of learners obtained zero scores on the easiest phoneme awareness task. These results show that exposure to literacy instruction has helped learners develop phoneme sensitivity in English.

The knowledge of letter-sound correspondences is a good indication of learners' previous print and reading instruction exposure. The data again suggest that children have different emergent literacy experiences before they start school. At the start of Grade 1, learners on average identified seven L1 letter-sound correspondences correctly per minute. This is significantly higher than the mean of 5.4 letters reported for Setswana in the control schools in the EGRS I (Taylor et al. 2015) but not significantly different from the mean of 7.5 letters correct per minute in Kiswahili (a Bantu language with transparent orthography like isiZulu and Siswati) in Kenya (Piper et al. 2018). Lower scores on EGRS 1 (Setswana) may be attributed to the more difficult letter-sound recognition task which included two capital letters at the start of the task, or contextual differences in the provinces. At the end of Grade 1, learners did show some improvement in this skill $(M=17.62)$, however, perhaps not as much as would have been expected. The end of Grade 1 task elicited English letter - sounds. However, for the most part, these are the same sounds as for isiZulu and Siswati, and only five letters were included which specifically needed an English pronunciation. Half the learners did not even reach the first English letter-sound. The average is significantly lower than the end of Grade 1 results in Setswana EGRS I control schools $(M=22.7)$, which could reflect the instructional practices in each province, or the effect of learning the more transparent Setswana. In summary, after a year of formal literacy instruction, there remains $10.6 \%$ of learners who cannot identify one letter correctly. The knowledge of letter-sound correspondences is the precursor to accurate word decoding. With so many children being slow letter readers, it is not surprising word recognition skills are also not fluent.
The majority of learners began school unable to read words. At the start of Grade 1, an L1 word recognition task had floor effects and was therefore not included in the analysis. At the end of Grade 1, learners were assessed on an L1 and English word recognition task. Learners could read slightly more words in their L1 than English. The average performance on the word recognition tasks was $5.51 \mathrm{~L} 1$ words and 5.16 English words. What is concerning is that $45.7 \%$ of learners could not read a single L1 word correctly, and 35\% could not read an English word correctly at the end of the year. English word-reading may be in line with the curriculum where learners should be able to 'recognise a few high-frequency sight words' by the end of Grade 1 (DBE 2011:20). However, such low levels of literacy in learners' L1 is alarming but is not unexpected given the poor L1 word and oral reading fluency results reported in other South African studies (DBE 2017; Spaull et al. 2018). For example, Setswana readers at the end of Grade 1 read 7 words correctly (Taylor et al. 2016), and isiZulu readers at the start of Grade 3 could read 17.8 words correctly per minute (Spaull et al. 2018). That L1 and English wordreading fluency is developing almost in parallel rather than L1 reading far surpassing English reading could indicate that learners have not automated their letter-sound correspondence knowledge needed to automatically decode the very transparent isiZulu and Siswati words. Measures of text reading fluency were not included. Nevertheless, with $50 \%$ of learners reading less than 2 words per minute, it can be expected that learners would be very slow text readers and would likely not understand what they read.

In summary, these results suggest that English oral language proficiency is relatively weak at the start of Grade 1, but given the focus of the curriculum on this skill in Grade 1, some improvements are made. Similarly, learners' L1 decoding skill as measured by letter-sound recognition was quite weak at the start of Grade 1. Learners are explicitly taught decoding in their L1 during Grade 1 and the unimpressive improvements in the overall learner performance on the L1 decoding skills attest to the weak instruction of this precursory skill for fluent reading and comprehension in L1. English word-reading at the end of Grade 1 reached levels similar to L1 word-reading in this sample, but in the absence of established reading norms it is unclear whether these improvements are sufficient for learners to successfully learn from their textbooks from Grade 4, written in English, which are also used by and written for L1 English speakers.

\section{Predictors of English as a second language oral proficiency and literacy abilities}

The second research question explores the relationship between the skills at the start of Grade 1 and decoding and English oral proficiency at the end of Grade 1. A significant linear relationship between L1 skills at the start of Grade 1 and ESL skills at the end of Grade 1 is argued to constitute transfer of skills. 
The results in Table 4 show that holding all other baseline literacy skills constant, L1 initial phoneme isolation at the start of Grade 1 is a good predictor of both L1 word-reading and ESL phoneme awareness, letter knowledge, wordreading and spelling. Thus, $\mathrm{L} 1$ phoneme identification at the start of Grade 1 transfers to and facilitates the development of ESL phoneme awareness and code-based skills at the end of Grade 1. It is also important to highlight the significant predictive relationship of L1 phoneme awareness to end-ofthe-year L1 word-reading, which as yet has not been reported in Grade 1 for isiZulu and Siswati children. These findings confirm what has been found by other researchers in similar contexts in Grades 2 and 3: L1 phoneme awareness transfers to ESL word-reading (Veii \& Everatt 2005; Wilsenach 2013) and spelling (De Sousa et al. 2010). These findings highlight the importance of phoneme sensitivity in developing lettersound correspondence knowledge essential for reading and spelling (Adams 1990).

L1 letter-sound recognition measured at the start of Grade 1 was also a significant predictor of all the L1 and L2 decoding and oral proficiency skills assessed in this study even after controlling for phoneme identification. Letter-sound correspondence knowledge is affected by both orthographic and phonological awareness. The results therefore provide evidence of the transfer of letter - sound correspondence knowledge from the L1 to ESL. The data show that once children have developed letter - sound knowledge in the L1, they are able to use this knowledge in reading and spelling in ESL at the end of the year. The contributions of start of Grade 1 letter-sound knowledge to the end of Grade 1 ESL phoneme identification and letter-sound knowledge highlight the reciprocal relationship between letter knowledge and phoneme awareness. Letter-sound knowledge also predicted L1 and ESL oral language proficiency. This relationship can be explained with reference to the use of letter-sound correspondence knowledge in word-reading. Better word readers are more likely to learn new vocabulary and syntactic constructions from print, which in turn results in increased oral proficiency. There is some evidence from Northern Sotho speaking children that early skills (such as vocabulary and letter knowledge) are correlated in Grade 1 (Wilsenach 2015), but the reasons are not clear. The association of letter-sound knowledge to oral proficiency in both L1 and ESL, therefore, deserves further research.

As to be expected, the English vocabulary of learners at the start of Grade 1 is also positively correlated with the English oral language proficiency skills assessed at the end of Grade 1. ESL vocabulary also predicted spelling at the end of Grade 1. This relationship to spelling can be explained by referring to the items included in the tasks. The ESL vocabulary task at the start of Grade 1 assessed learners' receptive and productive knowledge of animal names in English. The first item required learners to point to the dog in the picture. Thus, our results show that children who knew the English word dog were better able to spell the same word at the end of the year. This result highlights the importance of oral language proficiency for writing.
Weaker predictive relationships were found between L1 vocabulary at the start and end of the year, highlighting that children who begin school with better vocabulary tend to get better over time (Pretorius \& Stoffelsma 2017). L1 phonological working memory predicted ESL phoneme identification. This result confirms that performance on phoneme identification tasks is constrained by children's inherent phonological working memory capacity. Finally, L1 listening comprehension abilities transferred to ESL phoneme identification and listening comprehension abilities at the end of the year. Transfer to phoneme identification provides evidence for the Lexical Restructuring Hypothesis (Metsala \& Walley 1998) which states that learners with better oral language proficiency are better able to restructure their phonological representations of words. Transfer from L1 to ESL listening comprehension was weaker, confirming the findings of Melby-Lervåg and Lervåg (2011) that code-based skills (such as phonological awareness) are more amendable to transfer than oral language proficiency. On the other hand, this relationship could be an artefact of the instruments used, where L1- and ESL listening comprehension tasks were translations of each other. Nevertheless, this relationship shows that once children know concepts in their L1, they can transfer this knowledge to ESL, even when ESL proficiency is low.

\section{Limitations and conclusion}

A limitation of this study is the 'snapshot' approach of the tasks, where literacy constructs are not examined in detail. Because of the time constraint and costs involved in largescale data collection, in-depth examination of any one skill was not possible, nor necessary for the goals of the EGRS II. This, however, prohibits us from evaluating the low levels of language and literacy skills. Moreover, the lack of language benchmarks in African languages, as well as in ESL, for Grade 1 in South Africa means that there are no norms against which these results can be evaluated. This study therefore aims to contribute to the evidence base by reporting on the levels of these skills in Grade 1.

This study provides an overview of the relationships between and development of various L1 and ESL oral proficiency and literacy skills over time. The authors suggest the following areas for future research:

- Development of reading benchmarks for ESL lettersound knowledge, word-reading, passage reading and vocabulary in the Foundation Phase to enable the tracking of reading development and ensuring that learners reach the required level of reading comprehension to cope with the curriculum demands in Grade 4.

- Further research to understand which L1 language and literacy skills transfer to ESL language and literacy skills over time.

- An examination of home and school level factors which affect literacy acquisition over time. The current study did not report on these contextual factors which do play a role in literacy acquisition. 
- An examination of why some learners fail to read after 1 year of instruction in their L1.

This study details the literacy skills with which learners begin Grade 1. While learners began school with various levels of L1 oral proficiency, limited knowledge of English and limited decoding ability, these skill levels improved during the school year. However, there is still a large proportion of learners who fail to make adequate progress in their literacy development in both L1 and ESL. The low level of literacy in both school languages is a cause for concern.

For early grade reading skills related to ESL development, the data confirm that code-based skills are more amenable to transfer (Melby-Lervåg \& Lervåg 2011). L1 phoneme awareness and L1 letter-sound knowledge measured at the start of Grade 1 transferred to ESL phoneme awareness, letter-sound knowledge, word-reading and spelling at the end of Grade 1. This study showed that learners who begin school with better phoneme awareness and greater knowledge of letter-sound correspondences in their L1 are likely to have better word-reading abilities in both languages at the end of Grade 1. Additionally, L1 letter-sound knowledge also transferred to ESL oral proficiency. These findings show that the transfer of L1 language and literacy skills to ESL language and literacy skills takes place even though L1 literacy skills are low at the start and end of Grade 1. Finally, learners' exposure to English outside of school is limited. It is, therefore, unlikely that children are exposed to large quantities of English outside of the school context in this rural environment. While learners may transfer their decoding skills to English, in a rural context it is unlikely that learners will have access to English outside the school environment. Teachers are, therefore, central in developing adequate English language and literacy proficiency in learners. Print-rich classrooms and quality instruction in both the mechanics of decoding (e.g. systematic phonics instruction) and in explicit vocabulary instruction in Grade 1 are critical in overcoming inequalities that already exist when learners enter school.

\section{Acknowledgements}

The authors would like to thank the United States Agency for International Development for the ongoing costs of implementation and evaluation of the Second Early Grade Reading Study.

\section{Competing interests}

The authors declare that they have no financial or personal relationships that may have inappropriately influenced them in writing this article.

\section{Authors' contributions}

Both authors collaborated on writing the article through their work on the Second Early Grade Reading Study. M.S. was responsible for the literature review and presentation of the research study. Data analysis was undertaken by J.K. Both authors contributed to interpreting the results and writing the conclusion.

\section{Disclaimer}

The authors declare that the views expressed in this article are their own and not necessarily representative of the organisations they are affiliated with.

\section{References}

Adams, M., 1990, Beginning to read: Thinking and learning about print, MIT Press, Cambridge.

August, D., Carlo, M., Dressler, C. \& Snow, C., 2005, 'The critical role of vocabulary development for English language learners', Learning Disabilities Research and Practice 20(1), 50-57. https://doi.org/10.1111/j.1540-5826.2005.00120.x

August, D. \& Shanahan, T. (eds.), 2006, Developing literacy in second-language learners: Report on the national literacy panel on language-minority children and youth, Lawrence Erlbaum Associates, Mahwah, NJ.

Casale, D. \& Posel, D., 2011, 'English language proficiency and earnings in a developing country: The case of South Africa', The Journal of Socio-Economics 40(4), 385-393.

Cummins, J., 1979, 'Linguistic interdependence and the educational development of bilingual children', Review of Educational Research 49(2), 222-251. https://doi. org/10.3102/00346543049002222

Cunningham, A.E. \& Stanovich, K., 2001, 'What reading does for the mind', Journal of Direct Instruction 1(2), 137-149.

De Sousa, D.S., Greenop, K. \& Fry, J., 2010, 'The effects of phonological awareness of Zulu-speaking children learning to spell in English: A study of cross-language transfer', British Journal of Educational Psychology 80, 517-533. https://doi. org/10.1348/000709910X496429

Department of Basic Education, 2011, National curriculum statement: Curriculum and assessment policy statement: Foundation phase Grades 1-3, Government Printing Works, Pretoria.

Department of Basic Education, 2017, Summary report: Results of year 2 impact evaluation - The early grade reading study (EGRS), Department of Basic Education, Pretoria.

Department of Planning, Monitoring and Evaluation/Department of Basic Education, 2017 , Report on the implementation of the national curriculum statement grade $R$ to 12 focusing on the curriculum and assessment policy statements (CAPS), Department of Planning, Monitoring and Evaluation/Department of Basic Education, Pretoria.

Dolch, E.W., 1936, 'A basic sight vocabulary', The Elementary School Journal 36(6), 456-460. https://doi.org/10.1086/457353

Draper, K. \& Spaull, N., 2015, 'Examining oral reading fluency among rural Grade 5 English second language (ESL) learners in South Africa: An analysis of NEEDU 2013', South African Journal of Childhood Education 5(3), 44-77.

Dubeck, M.M. \& Gove, A., 2015, 'The early grade reading assessment (EGRA): Its theoretical foundation, purpose, and limitations', International Journal of Educational Development 40, 315-322. https://doi.org/10.1016/j.ijedudev.2014. 11.004

Elleman, A.M., Lindo, E.J., Morphy, P. \& Compton, D.L., 2009, 'The impact of vocabulary instruction on passage level comprehension of school-age children: A metaanalysis', Journal of Research on Educational Effectiveness 2(1), 1-44. https://doi. org/10.1080/19345740802539200

Field, J., 2004, Psycholinguistics: The key concepts, Routledge, Oxon.

Fuchs, L.S., Fuchs, D., Hosp, M.K. \& Jenkins, J.R., 2001, 'Oral reading fluency as an indicator of reading competence: A theoretical, empirical, and historical analysis', Scientific Studies of Reading 5(3), 239-256. https://doi.org/10.1207/S1532799X SSR0503_3

Gathercole, S.E. \& Baddeley, A.D., 1993, 'Phonological working memory: A critical building block for reading development and vocabulary acquisition?', European Journal of Psychology of Education 3(3), 259-272. https://doi.org/10.1007/ BF03174081

Genesse, F., Geva, E., Dressler, C. \& Kamil, M., 2006, 'Synthesis: Cross-linguistic relationships', in D. August \& T. Shanahan (eds.), Developing literacy in secondlanguage learners: Report on the national literacy panel on language-minority children and youth, pp. 153-174, Lawrence Erlbaum Associates, Mahwah, NJ.

Geva, E., 2006, 'Second language oral proficiency and second language literacy', in D. August \& T. Shanahan (eds.), Developing literacy in second-language learners: Report on the national literacy panel on language-minority children and youth, pp. 123-144, Lawrence Erlbaum Associates, Mahwah, NJ.

Ghana Education Service, 2016, GHANA 2015 early grade reading assessment and early grade mathematics assessment: Report of findings, RTI International, Research Triangle Park, NC.

Goswami, U., 2001, 'Early phonological development and the acquisition of literacy', in S. Neuman \& D. Dickinson (eds.), Handbook of early literacy research, pp. 111-125, Guilford Press, New York.

Grabe, W., 2012, Reading in a second language: Moving from theory to practice, 5th edn., Cambridge University Press, New York. 
Hedgcock, J.S. \& Ferris, D.R., 2018, Teaching readers of English: Students, texts and contexts, 2nd edn., Routledge, New York.

Howie, S., Combrinck, C., Roux, K., Tshele, M., Mokoena, G. \& McLeod Palane, N. 2017, PIRLS 2016: South African children's reading literacy achievement, University of Pretoria, Pretoria.

Hulme, C. \& Snowling, M.J., 2015, 'Learning to read: What we know and what we need to understand better', Child Development Perspectives 1(7), 1-5.

Kim, Y.G. \& Piper, B. 2018, 'Cross-language transfer of reading skills: An empirical investigation of bidirectionality and the influence of instructional environments' Reading and Writing, online first. Springer, Netherlands. https://doi.org/10.1007/ s11145-018-9889-7

Koda, K., 2008, 'Impacts of prior literacy experience on second-language learning to read', in K. Koda \& A.M. Zehler (eds.), Learning to read across languages: Crosslinguistic relationships in first and second-language development, pp. 68-96, Routledge, New York.

Kotzé, J., Fleisch, B. \& Taylor, S., (2019), 'Alternative forms of early grade instructional coaching: Emerging evidence from field experiments in South Africa' International Journal of Education Development, 66, 270-284. https://doi.org/ 10.1080/00220388.2012.693168; https://doi.org/10.1016/j.ijedudev.2018.09.004

Melby-Lervåg, M. \& Lervåg, A., 2011, 'Cross-linguistic transfer of oral language, decoding, phonological awareness and reading comprehension: A meta-analysis of the correlational evidence', Journal of Research in Reading 34(1), 114-135. https://doi.org/10.1111/j.1467-9817.2010.01477.x

Metsala, J.L. \& Walley, A.C., 1998, 'Spoken vocabulary growth and the segmental restructuring of lexical representations: Precursors to phonemic awareness and restructuring of lexical representations: Precursors to phonemic awareness and beginning literacy, pp. 89-120, Lawrence Erlbaum Associates, Mahwah, NJ.

Nation, I., 2013, Learning vocabulary in another language, 2nd edn., Cambridge University Press, New York.

Ntuli, D. \& Pretorius, E.J., 2005, 'Laying foundations for academic language competence: The effects of storybook reading on Zulu language, literacy and discourse development', Southern African Linguistics and Applied Language Studies 23(1), 91-109. https://doi.org/10.2989/16073610509486376

Piper, B., Zuilkowski, S.S., Kwayumba, D. \& Oyanga, A., 2018, 'Examining the secondary effects of mother-tongue literacy instruction in Kenya: Impacts on student learning in English, Kiswahili and mathematics', International Journal of Educational Development 59, 110-127. https://doi.org/10.1016/j.ijedudev.2017.10.002

Pretorius, E.J., 2010, 'Issues of complexity in reading: Putting Occam's razor aside for now', Southern African Linguistics and Applied Language Studies 28(4), 339-356. https://doi.org/10.2989/16073614.2010.548016

Pretorius, E.J. \& Spaull, N., 2016, 'Exploring relationships between oral reading fluency and reading comprehension amongst English second language readers in South Africa', Reading and Writing 29(7), 1449-1471. https://doi.org/10.1007/s11145-016-9645-9

Pretorius, E.J. \& Stoffelsma, L. 2017, 'How is their word knowledge growing? Exploring Grade 3 vocabulary in South African township schools', South African Journal of Childhood Education, 7(1), a553.

RTI International, 2015, USAID/Uganda school health and reading program: The status of early grade reading and teaching reading in primary school: Cluster 3 baseline report, RTI International, Research Triangle Park, NC.
RTI International, 2018, viewed 07 March 2018, from http://www.tangerinecentral. org/

Shin, J., Sailors, M., McClung, N., Pearson, P.D., Hoffman, J.V. \& Chilimanjira, M., 2015, 'The case of Chichewa and English in Malawi: The impact of first language reading and writing on learning english as a second language', Bilingual Research Journal 38(3), 255-274. https://doi.org/10.1080/15235882.2015.1091050

Snowling, M.J. \& Hulme, C., 2005, 'Editorial part I', in M.J. Snowling \& C. Hulme (eds.), The science of reading: A handbook, pp. 3-5, Blackwell Publishing Ltd, Malden.

South Africa, 1996, The South African schools act (act number 84 of 1996), Government Printers, Pretoria.

Spaull, N., Pretorius, E. \& Mohohlwane, N., 2018, 'Investigating the comprehension iceberg: Developing empirical benchmarks for early grade reading in agglutinating African languages', RESEP Working Paper Series No. WP01/2018, Research on Socio-Economic Policy, Stellenbosch.

Taylor, S., Cilliers, J., Fleisch, B., Prinsloo, C., van der Berg, S. \& Reddy, V. 2015, The early grade reading study: A report on the baseline data collection and year 1 programme activities, Department of Basic Education, Pretoria.

Taylor, S., Cilliers, J., Fleisch, B., Prinsloo, C., Van der Berg, S. \& Reddy, V. 2016, The early grade reading study: A midline report, Department of Basic Education, Pretoria.

Taylor, S. \& Coetzee, M., 2013, 'Estimating the impact of language of instruction in South African primary schools: A fixed effects approach', RESEP Working Paper Series No. WP21/2013, Research on Socio-Economic Policy, Stellenbosch.

Taylor, S. \& Yu, D., 2009, The importance of socio-economic status in determining educational achievement in South Africa, RESEP Working Paper Series No. WP01/2009, Research on Socio-Economic Policy, Stellenbosch.Timæus, I.M. Simelane, S. \& Letsoalo, T., 2013, 'Poverty, race, and children's progress at school in South Africa', The Journal of Development Studies 49(2), 270-284. https://doi. in South Africa', The Journal of Developn
org/10.1080/00220388.2012.693168

Umalusi, 2015, Umalusi South African foundation phase comparative curriculum analysis: English home and first additional language, Umalusi, Pretoria.

Van der Walt, C. \& Evans, R., 2017, 'Is English the Lingua Franca of South Africa?', in J. Jenkins, W. Baker \& M. Dewey (eds.), The Routledge handbook of English as Lingua Franca, pp. 186-198, Routledge, Oxford and New York.

Veii, K. \& Everatt, J., 2005, 'Predictors of reading among Herero-English bilingua Namibian school children', Bilingualism 8(3), 239-254. https://doi.org/10.1017/ S1366728905002282

Wagner, R., Torgesen, J. \& Rashotte, S., 1999, Comprehensive test of phonological processing. Examiner's manual, Pearson Assessments, San Antonia, Texas.

Wilsenach, C., 2013, 'Phonological skills as predictor of reading success: An investigation of emergent bilingual Northern Sotho/English learners', Per Linguam 29(2), 17-32. https://doi.org/10.5785/29-2-554

Wilsenach, C., 2015, 'Receptive vocabulary and early literacy skills in emergent bilingual Northern Sotho-English children', Reading \& Writing 6(1), 11. https:// doi.org/10.4102/rw.v6i1.77 